\title{
PODCAST COMO ESTRATÉGIA DE APRENDIZAGEM NO ENSINO SUPERIOR
}

\author{
ADRIANA RODRIGUES PEREIRA ${ }^{1}$, FRANCISCO ARISTIDES DOS \\ SANTOS NETO ${ }^{2}$.
}

\begin{abstract}
1 Mestre em Engenharia Civil pelo Centro Federal de Educação Tecnológica de Minas Gerais (CEFETMG). Docente do curso de Engenharia Civil do Centro Universitário Presidente Tancredo de Almeida Neves (UNIPTAN). adrianaengcivil@hotmail.com

2Mestre em Engenharia Civil pelo Centro Federal de Educação Tecnológica de Minas Gerais, CEFET/MG, Brasil. Docente do curso de Engenharia Civil do Centro Universitário Presidente Tancredo de Almeida Neves. francisco.neto1989@yahoo.com.br
\end{abstract}

\section{RESUMO}

As metodologias ativas de aprendizagem consistem em alternativas para o ensino tradicional. Tais métodos de ensino visam tornar os alunos sujeitos ativos no processo de aprendizagem, de modo a promover uma práxis pedagógica capaz desenvolver diferentes competências no ambiente de ensino. Com o advento da internet, houveram mudanças significativas nos meios de comunicação, reiterando a importância de um processo educacional que englobe as mídias digitais. Uma das ferramentas de comunicação que tem se tornado cada vez mais popular é o podcast, uma mídia digital similar aos programas de rádio. Este artigo tem como objetivo apresentar a utilização de podcasts como uma ferramenta de metodologia ativa aplicada ao ensino superior. $\mathrm{O}$ estudo descritivo abrange um relato de experiência, realizado em uma instituição privada de ensino superior, localizada em São João del-Rei, MG. Os podcasts foram elaborados por discentes que foram divididos em grupos e, após uma etapa preliminar referente ao planejamento, utilizaram o aplicativo Anchor em smartphones para realizar as gravações. Após a gravação dos podcasts, os alunos realizaram um feedback sobre a experiência deles com a utilização dessa ferramenta no processo de aprendizagem. Os resultados sugerem que o desenvolvimento colaborativo de podcasts permite que os discentes compartilhem conceitos do conteúdo disciplinar de uma maneira que estimula tanto a aprendizagem individual quanto a coletiva. Além disso, competências como o trabalho em equipe e a autonomia no ensino também são destacadas nesse método. A utilização de podcasts como uma metodologia ativa que se mostrou efetiva e colaborou para implantação de um aprendizado ativo e adaptado às novas ferramentas digitais.

Palavras-chave: Metodologias Ativas; Podcast; Ensino Superior.

PODCAST AS A LEARNING STRATEGY IN HIGHER EDUCATION 


\begin{abstract}
Active learning methodologies are alternatives to traditional methods. Such teaching methods aim to make students active subjects in the learning process, aiming a pedagogical praxis capable of developing different skills. With the advent of the internet, there have been significant changes in communication, reaffirming the importance of an educational process that encompasses digital media. One of the communication tools that has become increasingly popular is the podcast, a digital media similar to radio programs. This article aims to present the use of podcast as an active learning method applied to higher education. The descriptive study covers an experience report, carried out in a private higher education institution, located in São João del-Rei, Minas Gerais. This study was carried out during the second semester of 2019. The podcasts were developed by students who were divided into groups and, after a planning phase, used the Anchor application to make the recordings on their smartphones. After recording the podcasts, students provided feedback about their experience. The results suggest that the collaborative development of podcasts allows students to share concepts of the subject in a way that stimulates both individual and collective learning. In addition, skills such as teamwork and autonomy in the learning process are also highlighted in this method. The use of podcasts as an active methodology proved to be effective and contributed to the implementation of an active learning that is adapted to new digital tools.
\end{abstract}

Keywords: active learning; podcast; higher education.

\title{
1 INTRODUÇÃO
}

As instituições de ensino superior no Brasil seguem, em sua maioria, o modelo pedagógico tradicional. Segundo Cunha (1997), os docentes absorvem práticas de ensino tradicional durante a sua formação profissional e as replicam ao se tornarem professores. Mesmo com o advento de novas tecnologias, o ensino continua predominantemente oral e escrito e os alunos continuam a receber as informações passivamente durante o processo de aprendizagem.

As metodologias ativas de ensino são uma alternativa para atender às demandas atuais na educação. A aprendizagem ativa ocorre quando o aluno atua como protagonista, em atividades interativas com outros alunos, aprendendo de maneira colaborativa. Essas metodologias são baseadas na autonomia e protagonismo dos alunos, desenvolvendo habilidades e competências mediante a aprendizagem colaborativa e interdisciplinaridade (CAMARGO; DAROS, 2018). A construção do 
aprendizado passa a ser mediada pelo docente, que atua como um facilitador e não apenas um agente transmissor do conhecimento (CARVALHO; CHING, 2616).

Cruz (2009) afirma que os docentes devem se aproximar da linguagem dos discentes de modo a estabelecer um vínculo entre o conteúdo a ser aprendido e o interesse dos alunos. Nesse contexto, surge a utilização de podcasts como uma metodologia ativa de ensino. Freire (2016) afirma que a ferramenta podcast, quando utilizada adequadamente, favorece a autonomia dos alunos, além de possibilitar que ele seja promotor do seu aprendizado. Barros e Menta (2007) apresentam a definição para o termo podcast:

Podcast é uma palavra que vem do laço criado entre Ipod - aparelho produzido pela Apple que reproduz mp3 e Broadcast (transmissão), podendo defini-lo como sendo um programa de rádio personalizado gravado nas extensões $\mathrm{mp} 3$, ogg ou mp4, que são formatos digitais que permitem armazenar músicas e arquivos de áudio em um espaço relativamente pequeno, podendo ser armazenados no computador e/ou disponibilizados na Internet, vinculado a um arquivo de informação (feed) que permite que se assine os programas recebendo as informações sem precisar ir ao site do produtor (BARROS; MENTA, 2007, p. 2).

Apesar de não ser uma estratégia de ensino disseminada, é possível encontrar diversas pesquisas sobre essa ferramenta. A maioria delas aborda a utilização de podcasts como uma ferramenta para revisar conteúdos abordados em sala de aula. Entretanto, existem poucas publicações abordando podcasts produzidos pelos próprios discentes durante o processo de aprendizagem. Nesse contexto, apresenta-se a relevância deste trabalho. Este estudo apresenta a metodologia utilizada para introduzir o podcast como uma ferramenta que contribui para a implantação de metodologias ativas no ensino superior. Além disso, é apresentada a percepção dos estudantes após a utilização dessa ferramenta.

\section{REFERENCIAL TEÓRICO}

Angelo (1993) apresentou alguns princípios capazes de melhorar o processo de ensino-aprendizagem: (1) aprendizagem ativa é mais efetiva do que a aprendizagem passiva, (2) o aprendizado requer atenção e compreensão da importância do que está sendo aprendido, (3) o aprendizado é mais efetivo e eficiente quando os discentes têm objetivos razoáveis, explícitos e positivos e quando os objetivos deles estão em concordância com os objetivos dos docentes, (4) para que uma nova informação seja 
absorvida, ela precisa estar significantemente conectada com o conhecimento prévio, que precisa ser relembrado previamente, (5) desaprender o que se sabe é mais difícil do que aprender uma nova informação, (6) informação organizada por meio de esforços individuais é mais provável de ser retida, aprendida e utilizada, (7) estudantes precisam de um feedback durante o processo de aprendizagem, (8) as maneiras pelos quais os estudantes são avaliados impacta fortemente nas maneiras nas quais eles estudam e aprendem, (9) dominar uma nova habilidade ou conhecimento requer uma grande quantidade de tempo e esforço, (10) aprender a transferir, aplicar conhecimentos e habilidades anteriores a novos contextos requer muita prática, (11) altas expectativas incentivam grandes conquistas, (12) para serem mais eficazes, os docentes precisam equilibrar os níveis de desafio intelectual e apoio instrucional, (13) a motivação para aprender é alterável e (14) a interação entre professores e alunos é um dos fatores mais poderosos na promoção da aprendizagem. Nesse contexto, é possível observar que a criação de podcasts pelos discentes é uma metodologia capaz de se enquadrar em vários destes princípios apresentados por Angelo (1993).

Os estudantes desenvolvem mais competências e habilidades e retém mais conhecimento mediante a utilização de práticas interativas e colaborativas de ensino, conforme podemos observar na pirâmide de aprendizagem proposta por Dale (1946) (Figura 1). De acordo com o autor, ensinar está na base da pirâmide de aprendizagem e apresenta $85 \%$ de percentual de retenção do conhecimento, configurando-se na estratégia mais ativa da pirâmide. A prática apresenta $75 \%$ de percentual de retenção do conhecimento e discutir em grupo apresenta 50\%. A elaboração de podcasts pelos discentes permite não apenas discussões em grupo e a realização de uma atividade prática, mas também viabiliza que os alunos ensinem mediante o processo de gravação. 
Figura 1 - Pirâmide de aprendizagem de Edgard Dale.

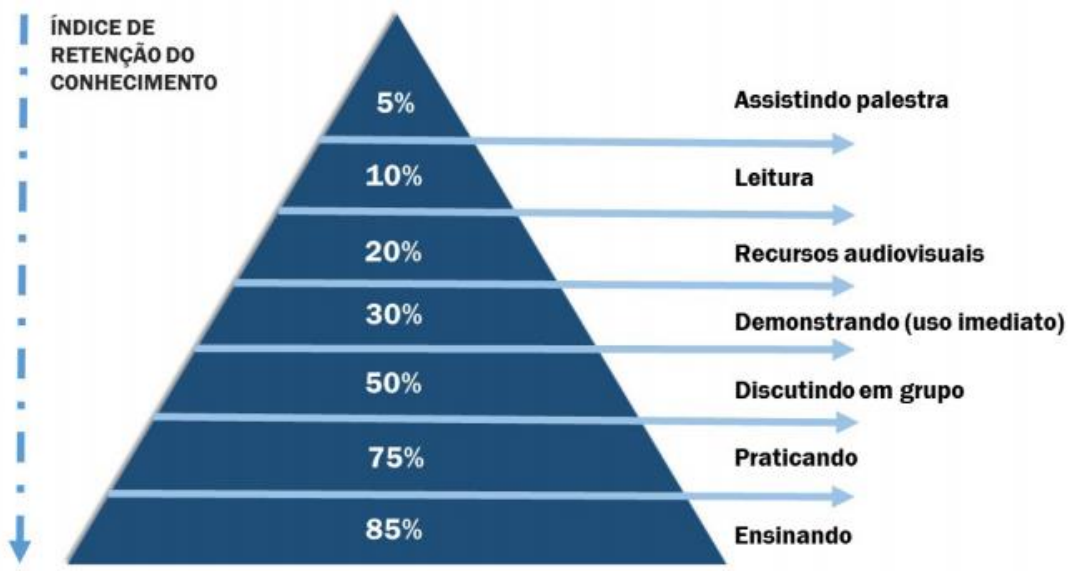

Fonte: SILVA et al., 2017.

De acordo com Demo (2016), apesar de as mídias digitas serem ótimos recursos a serem utilizados no processo educacional, eles não podem ser utilizados apenas como um artifício para tornar as aulas mais divertidas, mascarando o seu viés instrucionista. $\mathrm{O}$ autor sugere que o docente deve motivar os seus alunos a produzirem conteúdo de forma autoral, "tornando-se autor do conteúdo, não seu consumidor ou papagaio". Lames (2011) afirma que os docentes devem se preocupar em não cometer o erro de transferir metodologias de ensino tradicionais em meios digitais.

São diversos os fatores que contribuem para a configuração de um processo de ensino inovador. Terra (2007) destaca que a inovação está relacionada fundamentalmente com a criatividade e a produção de novas ideias. Camargo e Daros (2018) afirmam que, para que esse processo ocorra, é necessário que haja criatividade dos sujeitos envolvidos no processo de ensino-aprendizagem e motivação para colocar as ideias em prática. Para Vickery (2016), o docente deve conhecer bem os seus alunos e criar um ambiente promotor de debates, criatividade e reflexão, de modo que os alunos se sintam à vontade para se arriscarem e exporem a sua opinião.

\section{METODOLOGIA}

O podcast foi utilizado como uma ferramenta de ensino-aprendizagem em uma turma do $5^{\circ}$ período de engenharia civil. 
Visando o caráter interdisciplinar desta metodologia ativa de aprendizagem, duas disciplinas estiveram envolvidas na elaboração do podcast pelos alunos.

A metodologia educacional constitui-se nas etapas apresentadas na Figura 2.

Figura 2 - Etapas para o desenvolvimento da atividade.

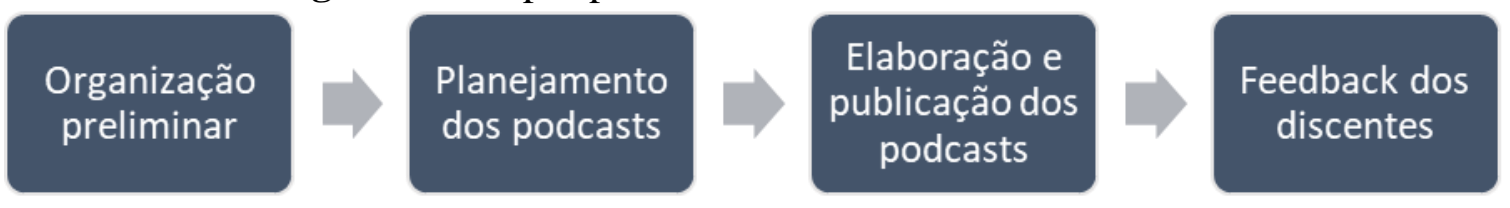

Fonte: Autoria própria (2020).

\subsection{Organização preliminar}

Primeiramente, foi realizada uma apresentação em sala de aula com a finalidade de introduzir o conceito e as características dos podcasts aos discentes, estabelecer a relação dessa ferramenta com as metodologias ativas de aprendizagem e apresentar um tutorial para a utilização do aplicativo Anchor como meio de gravação de podcasts.

Os discentes se organizaram em grupos de 4 a 5 alunos. Após essa definição, os discentes foram responsáveis por escolher um tema a ser abordado no podcast relacionado a uma das disciplinas que estavam envolvidas na organização deste trabalho. Esta definição teve como objetivo estimular os alunos a estudarem de forma autônoma um tema de interesse definido por eles, privilegiando a ação dos estudantes.

Cada um dos grupos foi acompanhado por um professor orientador. Esta definição condiz com as orientações de Carvalho e Ching (2016) em relação ao papel do professor como o facilitador ou mediador do processo de aprendizagem. Os discentes foram responsáveis pela pesquisa e organização do podcast e os docentes atuaram como orientadores do processo, quando solicitados.

Ainda nessa etapa, os grupos foram responsáveis por eleger um (uma) líder. Foi definida como atribuição do líder, pontuar a participação dos demais participantes do grupo na elaboração do podcast. Além disso, o líder também teve a sua participação avaliada pelos demais integrantes do grupo. Tal escolha teve como escopo evitar que alguns alunos não se engajassem durante o desenvolvimento do projeto. 
Foi estabelecido para os podcasts uma duração de 10 a 15 minutos. Tal limite foi estipulado pelos docentes, baseado na consulta a outros podcasts disponíveis em plataformas on-line e visando a criação de podcasts mais dinâmicos pelos discentes.

\subsection{Planejamento dos podcasts}

A primeira etapa do trabalho referente à elaboração de um podcast aplicado à engenharia civil consistiu no planejamento.

Nessa etapa, os discentes ficaram responsáveis pelo preenchimento de uma tabela com informações sobre a atividade a ser desenvolvida. A tabela foi disponibilizada pelos docentes e consistiu em parâmetros a serem levados em consideração durante o planejamento do podcast.

As seguintes informações foram elencadas pelos discentes:

- Tema do podcast;

- Público alvo;

- Nome do podcast;

- Título do episódio;

- Palavras-chave;

- Descrição geral do podcast;

- Descrição do episódio;

- Formato (entrevista, palestra, roda de conversa, etc.).

- Roteiro para gravação.

A Etapa 2 foi avaliada pelos docentes de acordo com os critérios apresentados na Tabela 1.

Tabela 1: Critérios para avaliação referentes à Etapa 3

\begin{tabular}{|l|}
\hline Podcast dentro do tempo estipulado (10 - 15 minutos $)$ \\
\hline Elaboração de um novo roteiro e alinhamento do mesmo com a gravação final \\
\hline Conteúdo abordado \\
\hline Linguagem utilizada nas gravações \\
\hline Criatividade/ edição \\
\hline
\end{tabular}

Fonte: Autoria própria (2020).

\subsection{Feedback dos discentes}


A Etapa 3 consistiu no feedback dos discentes a respeito da utilização de podcasts como uma ferramenta para a metodologia ativa de aprendizagem. O feedback consistiu em um questionário elaborado por meio do Formulários Google (GOOGLE, 2020).

De acordo com Evans e Mathur (2005), a utilização de plataformas on-line de pesquisa elimina erros de transcrição, viabiliza análises preliminares durante a coleta de dados, simplifica a extração e análise de dados, entre outros.

O feedback é uma importante ferramenta para que os docentes sejam capazes de avaliar a percepção discente diante de alguma atividade desenvolvida no processo educacional. Por meio desse instrumento, é possível verificar aspectos a serem melhorados ao replicar a atividade em uma outra oportunidade.

O questionário respondido pelos discentes foi facultativo e analisou os seguites aspectos: se o discente considerava o podcast uma metodologia ativa de ensino, se conhecia podcasts antes da realização da atividade, quais competências o podcast foi capaz de desenvolver, qual tipo de ensino o discente prefere (tradicional ou ativo) e se recomendaria a atividade para outros alunos.

\section{RESULTADOS}

Os resultados deste trabalho foram subdividos em duas seções: a percepção dos discentes e a percepção dos docentes mediante a utilização dessa metodologia ativa de ensino-aprendizagem.

\subsection{Percepção dos discentes}

Mediante a utilização do questionário on-line, foi possível obter um feedback dos discentes em relação à percepção da atividade aplicada. 27 alunos responderam ao questionário.

Todos os discentes afirmaram que são capazes de identificar a aplicação da metodologia ativa de ensino em sala de aula. Esse resultado corrobora o posicionamento dos docentes na instituição de ensino superior analisada. A maioria dos professores descrevem o que é a metodologia ativa de ensino e quais são os objetivos de aprendizagem antes de iniciar a aplicação de uma metodologia ativa em sala de aula. 
96,3\% dos discentes consideraram que o podcast é uma metodologia ativa de ensino e 59,3\% não conhecia podcasts antes da realização da atividade. Considerando que os podcasts podem contribuir para a aprendizagem além da sala de aula e em temas diversos, a introdução dessa ferramenta torna-se uma estratégia relevante para a formação dos alunos.

A Figura 3 apresenta as competências que os discentes relataram ter desenvolvido durante a aplicação da atividade.

Gráfico 1 - Percepção dos discentes em relação ao desenvolvimento de competências.

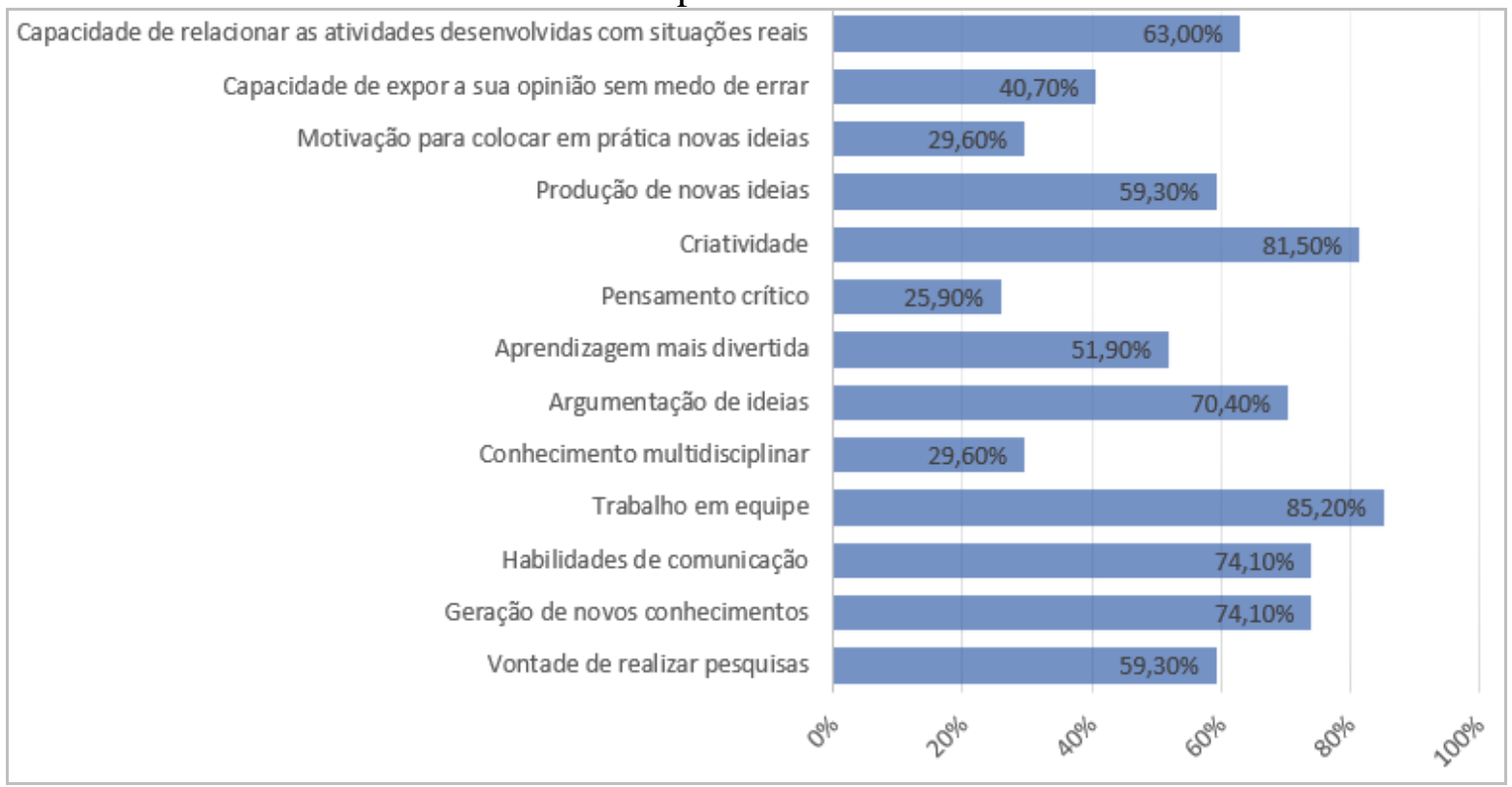

Fonte: Autoria própria (2020).

77,8\% dos discentes relataram a preferência pela metodologia ativa de ensino em oposição ao ensino tradicional. Tal fato reitera a necessidade de inovação na educação, criando mecanismos que possibilitem a interação, o uso de recursos tecnológicos e a incorporação de novos saberes, sem desconsiderar o conhecimento científico clássico, conforme apontado por Camargo e Daros (2018).

Verificou-se que maioria dos alunos $(74,1 \%)$ recomendaria a gravação de podcasts como atividade de ensino para outros alunos, 3,7\% talvez recomendaria e $22,2 \%$ não recomendaria. Tais respostas foram acompanhadas de justificativas e as mais relevantes foram elencadas na Tabela 3. Salientamos que as justificativas dos discentes foram transcritas de forma literal. Nota-se a frequência com que os discentes citaram o trabalho em equipe e a criatividade como pontos positivos nesse formato de avaliação. 
Em relação aos comentários negativos, um dos alunos mencionou que "grupos em que apenas um ou dois alunos se dedicam e o resto não fazem nada por falta de interesse", demonstrando certa dificuldade em realizar atividades em grupos. Tal fato corrobora a importância da realização de feedbacks após a aplicação desse tipo de atividade, uma vez que aponta competências que ainda precisam ser desenvolvidas em determinados alunos.

A análise dos relatos discentes permite que o processo de ensino-aprendizagem seja mais efetivo e personalizado. Além disso, contribui para que as competências e os objetivos de aprendizagem sejam efetivamente desenvolvidos durante a disciplina. Dessa forma, reitera-se a importância da aplicação constante de feedbacks durante o desenvolvimento da disciplina, e não apenas após a conclusão do semestre.

Tabela 2: Comentários dos discentes sobre o desenvolvimento do podcast O podcast foi uma experiência bem legal pois permitiu que houvesse uma melhor comunicação entre os participantes do grupo, um maior entrosamento e uma dinâmica boa. Além disso, as pesquisas para a reprodução do conteúdo fazem com que você aprenda facilmente os assuntos e tenha uma maior curiosidade no que foi pesquisado.

Foi muito bom trabalhar com algo novo em equipe.

Pois o podcast oferece uma oportunidade única de englobar metodologias ativais em um trabalhado super interessante, que no caso uma experiência muito boa!

Por trazer melhorias na comunicação e nas atividades em grupo.

Simplesmente pelo fato de termos que trabalhar em grupo, juntamente com as pesquisas para expor um conteúdo real. Uma preparação para o mercado de trabalho.

A atividade realizada nos proporcionou uma experiência de equipe muito interessante assim como desenvolvimento de criatividade. Então acredito que isso contribuiu para aproximar os integrantes de cada grupo e incentivou o aprendizado de uma maneira diferente a que já estamos acostumados. Ótima experiência!

Sim, pois pessoas podem se pronunciar. Podcast tira a timidez de todos e faz com que o aprendizado seja mais aprofundado ainda.

Gostaria que tivesse mais podcast. Relacionamos mais com alunos dentro de sala. Nos tornamos unidos.

Eu não recomendaria porque uma boa parte dos alunos não sabem o que é PodCast, logo não possuem tanto interesse e isso leva a falta de vontade dos alunos, que acabam por fazer o podcast so por fazer e ganhar uns pontinhos. $\mathrm{O}$ ponto que quero chegar é que PodCast não é interessante à maioria dos alunos e isso leva a grupos em que apenas um ou dois alunos se dedicam e o resto não fazem nada por falta de interesse, algo que é recorrente e não exclusivo do trabalho do PodCast. 


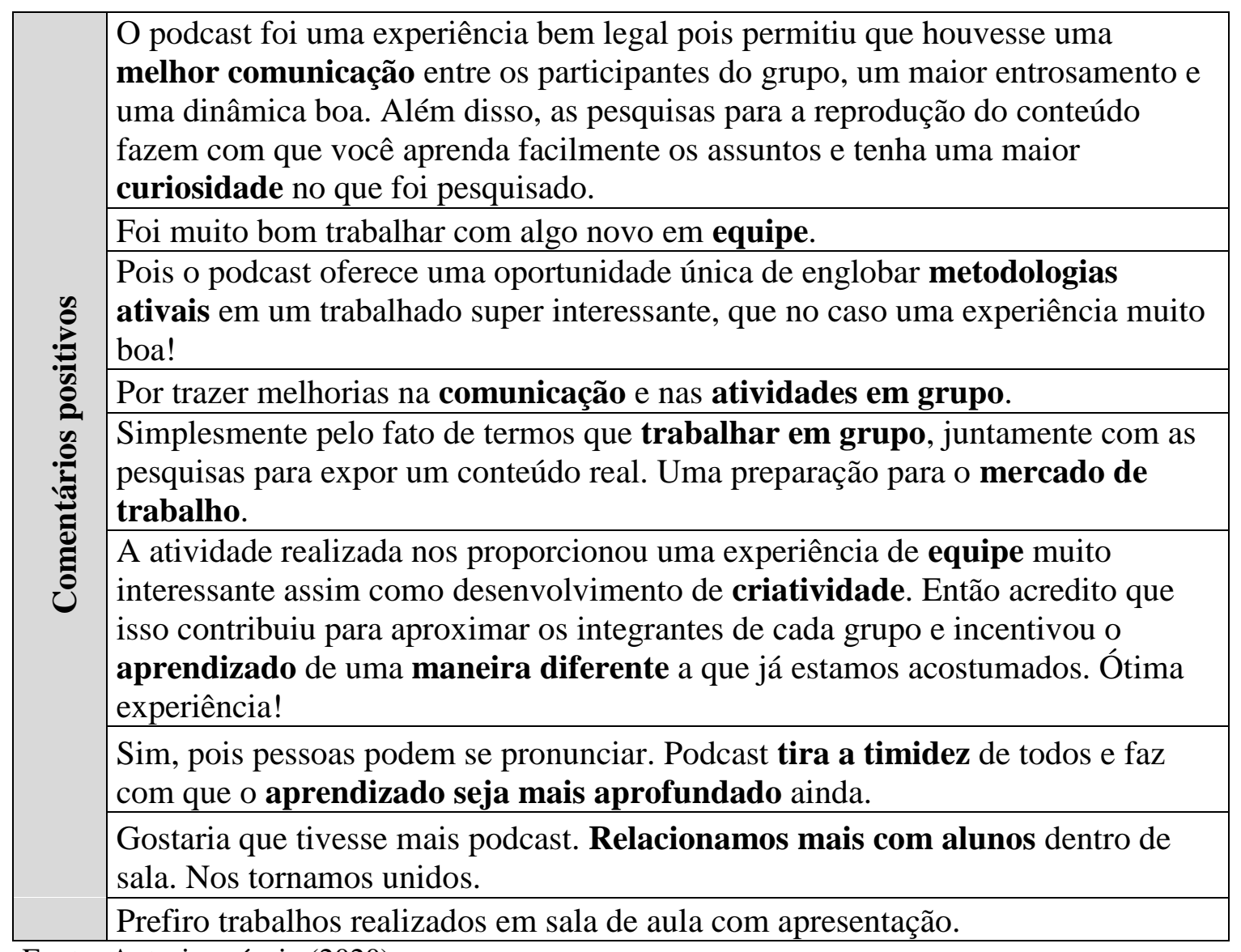

Fonte: Autoria própria (2020).

\subsection{Percepção dos docentes}

A avaliação final dos podcasts foi realizada em conjunto pelos docentes. Foi possível perceber nas gravações a dedicação dos alunos em produzir um conteúdo informativo, buscando diferentes referências para a elaboração dos podcasts. Quando comparado a outros trabalhos em grupo, notou-se um maior engajamento dos alunos, de acordo com a experiência prévia dos docentes. As atividades de criação e gravação dos podcasts contribuíram para o aprendizado ativo, auto-orientação e desenvolveu habilidades de trabalho em equipe nos alunos.

$\mathrm{Na}$ percepção dos autores, os discentes foram capazes de agir como indivíduos autônomos durante a produção dos episódios de podcasts. Conforme mencionado anteriormente, de acordo com Camargo e Daros (2018), a autonomia é um dos alicerces da aprendizagem ativa. A autonomia discente ocorreu durante a formação dos grupos, escolha dos temas, escolha do referencial bibliográfico, escolha de como elaborar o roteiro, escolha dos papéis de cada integrante no episódio do podcast gravado, forma 
como conduziram as gravações, entre outros. Os docentes atuaram apenas como orientadores nessa metodologia, fornecendo feedback aos alunos e orientações quando solicitados.

Durante o desenvolvimento dos podcasts, os docentes atribuíram o tempo de algumas aulas para os grupos se reunirem e tirarem dúvidas. Entretanto, percebeu-se que apenas alguns grupos se interessaram em procurar orientação ou discutir sobre o podcast em grupo. Esse fato foi evidente principalmente quando esse tempo para orientação ocorreu com muita antecedência em relação ao prazo de entrega. Dessa forma, percebe-se a importância da mediação dos docentes para auxiliar os alunos a aprenderem de forma autônoma.

Assim como em outras metodologias ativas, o resultado final está ligado diretamente ao engajamento dos alunos. Durante a realização da atividade, foi possível perceber que os alunos que obtiveram melhores resultados foram aqueles que se posicionaram mais ativamente durante o desenvolvimento da mesma. Dessa forma, apesar de todo o potencial que o podcast tem de desenvolver nos estudantes o trabalho em equipe, autonomia, pesquisa, criatividade, argumentação e outros, os benefícios são apenas atingidos em sua totalidade se o discente estiver disposto a ser um membro ativo no processo de aprendizagem.

Tais percepções reiteram a pirâmide de aprendizado de Edgar Dale (1946), que demonstra que quanto maior for a participação ativa do estudante no ensino, maior será a sua retenção de conhecimento. A pirâmide de aprendizado aponta que o índice de retenção do conhecimento é maior quando o aluno está ensinando (85\%). A atividade em formato de podcast possibilita justamente isso: o discente se torna o disseminador do conhecimento.

\section{CONCLUSÃO}

Este trabalho apresentou a metodologia utilizada para a aplicação de podcasts no processo de ensino-aprendizagem em uma instituição de ensino superior. Complementarmente, foi relatada a percepção dos discentes e docentes após a realização da atividade. 
$\mathrm{Na}$ compreensão dos autores, a utilização dos podcasts como uma metodologia ativa de ensino-aprendizagem no ensino superior foi muito positiva. A qualidade dos episódios gravados pelos discentes superaram as expectativas iniciais. $\mathrm{O}$ desenvolvimento de competências como a autonomia e o trabalho em equipe também são pontos a serem destacados.

Após esta primeira experiência, os autores pretendem aplicar esta metodologia novamente, com algumas ressalvas. Tendo em vista que os discentes estiveram submetidos a um processo de ensino tradicional desde os primeiros anos escolares, era de se esperar que houvessem algumas dificuldades na implantação da atividade em formato de podcast. Não são apenas os professores que devem se adaptar às novas metodologias de ensino, mas também os alunos, uma vez que todos exercem papel fundamental no processo educacional. Sabendo-se da subjetividade individual e social dos sujeitos, a experiência durante o desenvolvimento da atividade foi distinta entre os discentes. Apesar da contribuição docente e da realização de discussões em grupo, o desenvolvimento de diferentes competências variou de acordo com o engajamento individual. Outra característica importante de ser mencionada, é que esse tipo de atividade permite que a informação técnica seja compartilhada fora do ambiente acadêmico, democratizando o acesso ao conhecimento.

Notou-se a necessidade de criar estratégias para potencializar os resultados da atividade, aumentando a porcentagem de alunos engajados ativamente, de modo a obter resultados mais satisfatórios. Sugere-se, por exemplo, que, ao apresentar a atividade de podcast, seja reiterada a importância do protagonismo e da autonomia dos discentes para que a aprendizagem seja efetiva. Além disso, sugere-se que seja desenvolvido algum mecanismo para estimular os alunos a procurarem orientação docente ou discutirem em grupos durante todo o desenvolvimento da atividade, e não somente próximo ao período avaliativo.

\section{REFERÊNCIAS}

ANGELO, T. A. A teacher's dozen: Fourteen general, research-based principles for improving higher learning in our classrooms. AAHE Bulletin, 1993, p. 3-13.

BARROS, G. C.; MENTA, E. Podcast: produções de áudio para educação de forma crítica, criativa e cidadã. Revista de Economía Política de Las Tecnologías de La 
Información y Comunicación (epitic), [s. L.], v. 9, n. 1, p.1-14, abr. 2007. Disponível em: <http://portaldoprofessor.mec.gov.br/storage/materiais/0000012621.pdf>. Acesso em: 01 mar. 2020.

CAMARGO, F; DAROS, T. A sala de aula inovadora: estratégias pedagógicas para fomentar o aprendizado ativo. Porto Alegre: Penso, 2018.

CARVAlHO, F. F. O.; CHING, H. Y. Práticas de Ensino aprendizagem no Ensino superior: experiências em sala de aula. Rio de Janeiro: Alta Books, 2016.

CRUZ, S. C. O podcast no ensino básico. In: CARVALHO, A. A. (Org.). Actas do Encontro sobre Podcasts. Braga: CIEd, p. 65-80, 2009. Disponível em: <http://repositorium.sdum.uminho.pt/bitstream/1822/9991/1/Cruz-2009-

Enc\%20sobre\%20Podcasts.pdf $>$. Acesso em: 01 mar. 2020.

CUNHA, M. I. Aula universitária: inovação e pesquisa. In: LEITE, D.; MOROSINI, M. (orgs.). Universidade futurante: Produção do ensino e inovação. Campinas: Papirus, 1997.

DALE, Edgar. Audio-visual methods in teaching. New York: Dryden Press, 1946. Disponível em: < https://link.springer.com/article/10.1007\%2FBF02713296 >. Acesso em: 04 jul 2020.

DEMO, P. Atividades de Aprendizagem: sair da mania do ensino para comprometerse com a aprendizagem do estudante. Campo Grande: Secretaria de Estado de Educação do Mato Grosso do Sul - SED/MS, 2018. Disponível em: < http://www.sed.ms.gov.br/wp-content/uploads/2018/11/eBook-Atividades-deAprendizagem-Pedro-Demo.pdf>. Acesso em: 01 mar. 2020.

EVANS, J. R.; MATHUR, A. The value of online survey. Internet Res, v. 15, n. 2, p. 195-219, 2005.

FREIRE, E. P. A. Aprofundamento de uma estratégia de classificação para podcasts na educação. Revista Linhas, v. 16, n. 32, p. 391-411, 2016.

GOOGLE. Formulários Google. 2020. Disponível em: < https://docs.google.com/forms/u/0/>. Acesso em: 01 mar. 2020.

SILVA, D. R. et al. Projeto Jovem Doutor: o aprendizado prático de estudantes de medicina por meio de atividade socioeducativa TT - Young Doctor Project-Health in Schools: potential learning of medical students through taking part in socio-educational activity. Rev. med. (Säo Paulo), v. 96, n. 2, p. 73-80, 2017. Disponível em: <https://www.revistas.usp.br/revistadc/article/view/119445/129427>. 